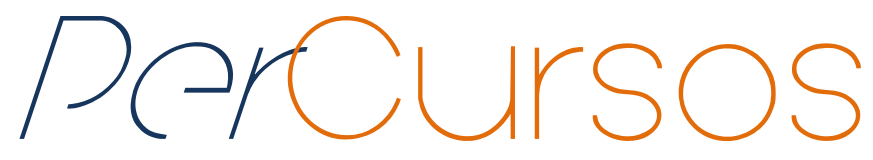

\title{
Das experiências desperdiçadas: dentre as muitas ausências estão também as crianças
}

\begin{abstract}
Resumo
Este texto tem por objetivo trazer para o debate o tema da defesa das crianças como cidadãs de direito. Procura-se, a partir das contribuições de Boaventura de Sousa Santos (1997, 1999, 2002, 2007), refletir como questões sociais amplas - globalização e capitalismo - afetam os modos das crianças viverem a infância, pois influem diretamente em suas vidas e nas formas como significam a realidade que as cerca. Primeiramente, a discussão focará as questões históricas e as distintas experiências sociais desperdiçadas, submetidas a invisibilidades e ausências. Por fim, as reflexões privilegiarão alguns aspectos que constituem a construção social da infância, bem como a defesa dos direitos das crianças e de sua participação efetiva nas decisões que lhe dizem respeito.
\end{abstract}

Palavras-chave: Infância. Criança. Globalização. Modernidade.

\section{Fernanda Gonçalves}

Mestrando no Programa de Pós-

Graduação em Educação da

Universidade Federal de Santa

Catarina - UFSC.

feegoncalves@gmail.com

\section{Para citar este artigo:}

GONLALVES, Fernanda. Das experiências desperdiçadas: dentre as muitas ausências estão também as crianças. Revista PerCursos. Florianópolis, v. 14, n.26, jan./jun. 2013. p. 09 - 25. 


\title{
Of the wasted experiences: among the many absences the children are too
}

\begin{abstract}
This paper aims to bring for discussion the theme of the defense of children as citizens of rights. It discusses from the contributions of Boaventura de Sousa Santos (1997, 1999, 2002, 2007), to reflect how ample social issues - globalization and capitalism - eventually affect the ways of children to live the childhood, therefore, directly influency in the lives of the children and the ways that mean the reality that surrounds them. First, the discussion will be focused on historical issues and the many wasted social experiences, submitted to invisibilities and absences. Finally, the reflexions will focus some aspects that constitute the social construction of childhood, as well as the defense of children's rights, of their effective participation in decisions concerning it.
\end{abstract}

Keywords: Childhood. Child. Globalization.

Modernity. 


\section{Introdução}

Há, de fato, no mundo de hoje, uma disparidade social gritante que ecoa por entre as ausências e clamam por visibilidade. De acordo com Boaventura de Sousa Santos (1999), os países capitalistas avançados controlam 78\% da produção mundial de bens de serviço; no entanto, representam apenas $21 \%$ da população mundial. Outro número assustador é o de crianças que trabalham em regime de cativeiro na Índia - uma média de 15 milhões. No nosso século, mais pessoas morreram de fome do que em qualquer outro século. Estes números ilustram a realidade mundial e nos convida a interrogar “criticamente sobre a natureza e a qualidade moral da nossa sociedade e a buscarmos alternativas teoricamente fundadas nas respostas que dermos a tais interrogações" (SANTOS, 1999, p. 199).

E a situação da infância em nível global? Apresenta-se bastante complexa. Parte dos indicadores monstra que a situação das crianças melhorou. No entanto, existem aspectos que regrediram significativamente. Como por exemplo, o número de crianças que morrem diariamente vítimas de problemas decorrentes de má nutrição: uma estimativa de 150 milhões (TOMÁS; SOARES, 2001). Isto nos demonstra que ainda existe uma drástica ausência de direitos básicos de provisão.

É inaceitável que em alguns contextos sociais o direito de provisão - alimentação, habitação, condições de saúde, assistência e educação, entre outros - não esteja garantido. Esta questão está associada ao fato de que a realidade social não se transforma somente pelos efeitos das publicações de normas jurídicas. Pois, mesmo com a existência e aprovação da Convenção dos Direitos das Crianças, de modo a estabelecer tais direitos, estes não se cumprem quando se trata da realidade. A garantia dos aspectos fundamentais dos direitos das crianças está ligada à situação econômica, cultural e social de um país; logo, está relacionada ao seu desenvolvimento econômico (PINTO; SARMENTO, 1997).

As condições de vida das crianças são heterogêneas, e isto explica a razão da paradoxal invisibilidade contemporânea da infância. Ainda que em muitas conjunturas direitos fundamentais como os de provisão, proteção e participação não sejam 
garantidos, estudos demonstram que, em termos mais gerais, é o direito da participação que mais tem sido negligenciado (PINTO; SARMENTO, 1997).

Além de não terem seus direitos básicos de provisão atendidos, as crianças são também vitimas de concepções excludentes. Nos documentos legais são definidas como cidadãs de direitos, mas estes não lhes são garantidos, inclusive o mais básico que é o da provisão. Por este motivo, são pertinentes os questionamentos de Tomás e Soares (2009):

O século que agora começa revela-se paradoxal: é um mundo de prodígios e de grandes conquistas, mas também da barbárie, da extrema ambição económica e de acentuadas desigualdades. E das imensas questões daí decorrentes há uma que se coloca como urgente: porque é que milhões de crianças continuam a ser excluídas e oprimidas? (TOMÁs; SOARES, 2004, p. 1).

Esta realidade vem se constituindo histórica e socialmente, tomando formas particulares com o desenrolar do capitalismo, aliado ao projeto de modernidade. Para Boaventura de Sousa Santos (1997), os fenômenos da virada do século XVI consagram o início da modernidade, que tem seu marco com as grandes navegações. Tal acontecimento colaborou para a disseminação de distintas culturas entre os países colonizados e colonizadores. Diferente do que pensavam os colonizadores, não somente levavam e impunham sua cultura, mas traziam consigo as distintas culturas dos países colonizados.

A modernidade, um projeto pensado com o intuito de criar benefícios para a humanidade, proposta laica e de transformação da natureza, compreende-se como um projeto global que tinha por objetivo inicial superar a ignorância instaurada na Idade Média, tida como idade das trevas. O capitalismo surge e ganha força, sua lógica toma a frente ditando as "normas" para o projeto de modernidade. Este novo modelo econômico usa a ciência como um mecanismo de acúmulo de riquezas; a lei que passa a reger o sistema é o lucro.

A bandeira do progresso é hasteada e acentuada pela revolução industrial, que se consolida por meio do capitalismo monopolista, tornando as teorias positivistas alicerce de sustentação. Nesta conjuntura, a história passa a ser compreendida como um "[...] 
encadeamento que engloba sucessivas dimensões bem definidas - passado, presente, futuro - cristalizadas pelas leis de causalidade e desdobradas nos conceitos de causa e consequência" (SOUSA; PEREIRA, 1998, p. 1).

O acúmulo de riquezas suscita a necessidade de novas descobertas, e estas, por sua vez, têm como intento o aumento da produtividade. Em nome do lucro e da produtividade, o capitalismo não mede consequências e se constitui perverso em todas suas facetas. Nesse processo, a ciência moderna demonstra estar a serviço do capitalismo e tem como lei primordial a busca pela regularidade; o que a fundamenta é justamente a busca da transformação do caos em ordem. Estes princípios regulatórios excluem e desperdiçam experiências, criando invisibilidades. Por meio de uma profunda reflexão a respeito destes fatores, Santos (2002) indica três importantes conclusões:

Em primeiro lugar, a experiência social em todo o mundo é muito mais ampla e variada do que a tradição científica ou filosófica ocidental conhece e considera importante. Em segundo lugar, esta riqueza social está a ser desperdiçada. É deste desperdício que se nutrem as ideias que proclamam que não há alternativa, que a história chegou ao fim, e outras semelhantes. Em terceiro lugar, para combater o desperdício da experiência, para tonar visíveis as iniciativas e os movimentos alternativos e para lhes dar credibilidade, de pouco serve recorrer à ciência social tal como conhecemos. No fim de contas, essa ciência é responsável por esconder ou desacreditar as alternativas. Para combater o desperdício da experiência social, não basta propor um outro tipo de ciência social. Mais do que isso, é necessário propor um modelo diferente de racionalidade. Sem uma crítica ao modelo de racionalidade ocidental dominante pelo menos durante duzentos anos, todas as propostas apresentadas pela nova análise social, por mais alternativas que se julguem, tenderão a reproduzir o mesmo efeito de ocultação e descrédito (SANTOS, 2002, p. 238).

As contribuições de Boaventura de Sousa Santos (2007) são expressivas para este debate. Segundo ele, o pensamento moderno ocidental é abissal, pois, desconsidera e exclui outras formas de pensamento. O que se define como o universo deste lado da linha e o universo do outro lado da linha, ou seja, o pensamento ocidental e o pensamento nãoocidental. 


\section{Por um não desperdício das distintas experiências sociais}

O pensamento ocidental moderno desconsidera outras formas de conhecimento que estejam fora da sua racionalidade. Nessa perspectiva, é a ciência moderna que detém o monopólio do saber e determina o que é verdadeiro ou não, e, em nome da regularidade, acaba por produzir ausências, por desprezar as distintas formas de existência, principalmente dos países não-ocidentais.

Deste modo, a luta que se trava em nome de uma justiça global deve ser também uma luta por uma justiça cognitiva global, para que não se desperdicem as distintas e múltiplas experiências sociais - que por vezes são anuladas e tomadas como inexistentes. É necessário perceber a realidade como um campo de possibilidades e colocar em confronto os diferentes saberes, os diferentes conhecimentos e experiências.

Para o pensamento ocidental moderno tempo significa poder, logo, quem obtiver o poder de definir quais temporalidades deverão ser seguidas deterá tal poder. É importante, portanto, que repensemos sobre os conceitos de temporalidade:

É sob o signo da razão que se estruturou a chamada vida moderna. Contradição e pressa. Muita pressa. O tempo não pára e não paramos nós. Assumimos a correria infinita como se fosse nosso movimento próprio. Desde a revolução industrial temos nos deixado seduzir pelas idéias de utilidade, produtividade e lucro, passando a identificar tempo e dinheiro. Tempo é dinheiro. Estamos definitivamente regulados pelo tictac incessante do relógio (SOUZA; PEREIRA, 1998, p. 5).

E onde ficam as crianças nessa realidade aligeirada? É necessário pensar criticamente sobre a realidade, problematizar o que é passível de crítica e o que possa vir a ser superado. Santos (2002) indica-nos a necessidade de realizar uma crítica à racionalidade - a chamada razão indolente ${ }^{1}$-, uma vez que a racionalidade ocidental impõe-se às demais culturas denominando-se verdade universal.

\footnotetext{
${ }^{1}$ A razão indolente manifesta-se de quatro maneiras: a primeira é a razão impotente. Esta acredita que nada pode ser feito contra "uma necessidade exterior a ela própria" (SANTOS, 2002, p. 3). A segunda é a razão arrogante: esta, por sua vez, entende-se como incondicionalmente livre. Já a razão metonímica, a terceira razão apresentada pelo autor, compreende-se como uma forma de racionalidade única; reside nela o autoritarismo da modernidade, julgando-se inquestionável. E, por fim, a razão proléptica, que acredita saber tudo sobre o futuro e por isto não se faz necessário pensar sobre ele; o "concebe como uma superação linear, automática e infinita do presente" (SANTOS, 2002, p. 4).
} 
A defesa de uma racionalidade cosmopolita é uma das propostas de Boaventura de Sousa Santos (1999), que tem como objetivo expandir o presente e contrair o futuro. Ou seja, criar um espaço-tempo indispensável para que se possibilite conhecer as distintas e múltiplas experiências sociais. Somente desta forma seria possível então, não desperdiçar tantas experiências sociais.

Outra importante contribuição de Santos (2002) é a proposição de uma sociologia das ausências e uma sociologia das emergências. A primeira tem como finalidade expandir o presente, de modo que se identifiquem as experiências sociais produzidas como ausentes, tornando-se também uma possibilidade de verdade. O inconformismo com o descrédito aos diferentes saberes e a luta pela sua credibilidade motivam a sociologia das ausências. Sua ideia central consiste na compreensão de que não existe uma ignorância em geral e também não existe um saber em geral; portanto, todos os saberes são uma manifestação de verdade. Desta compreensão emerge uma possibilidade de diálogo e de disputa epistemológica entre os distintos saberes.

Enquanto a sociologia das ausências propõe a dilatação do presente, a sociologia das emergências visa à contração do futuro. Significa, então, substituir o vazio do futuro, de acordo com o tempo linear, por um futuro de possibilidades concretas e plurais. É uma espécie de inconformismo mediante as carências que ainda estão no horizonte de possibilidades. Portanto, a sociologia das ausências diz respeito ao campo das experiências sociais; a sociologia das ausências move-se no campo das expectativas sociais. Ambas estão interligadas, já que:

[...] quanto mais experiências estiverem hoje disponíveis no mundo, mais experiências são possíveis no futuro. Quanto mais ampla for a realidade credível, mais vasto é o campo dos sinais ou pistas credíveis e dos futuros possíveis concretos. Quanto maior for a multiplicidade e diversidade das experiências disponíveis e possíveis (conhecimentos e agentes), maior será a expansão do presente e a contração do futuro. Na sociologia das ausências, essa multiplicação e diversificação ocorre pela via da ecologia dos saberes, dos tempos, das diferenças, das escalas e das produções, ao passo que a sociologia das emergências as revela por via da amplificação simbólica das pistas ou sinais (SANTOS, 2002, p. 259).

Para considerar a relevância dos distintos saberes, evitando assim o desperdício das muitas experiências sociais, Santos (2002) sugere uma ecologia de saberes. Significa 
dar credibilidade aos diferentes saberes, colocando-os em diálogo. Para tal diálogo, é importante que as distintas e múltiplas formas de pensamento existentes no mundo possam participar dos debates epistemológicos, sem que sejam simplesmente desconsiderados e invisibilizados. Segundo ele:

O que cada saber contribui para esse diálogo é o modo como orienta uma dada prática na superação da ignorância. O confronto e o diálogo entre os saberes é um confronto e diálogo entre diferentes processos através dos quais práticas diferentemente ignorantes se transformam em práticas diferentes sábias (SANTOS, 2002, p. 250).

Acreditamos que nenhuma experiência social deva ser desconsiderada, mas colocada em debate, de modo que se ampliem os saberes. Inclusive as experiências sociais vividas pelas crianças, a quem procuramos privilegiar neste texto, como partícipes potentes das relações sociais, que merecem ser tratadas como cidadãs de direito - não somente nos documentos legais e oficiais -, mas merecedoras legítimas deste direito no seu dia-a-dia, em suas relações, em seus modos de ver e compreender o mundo, de expressar suas emoções e opinar sobre questões que dizem respeito às suas vidas cotidianas. Os saberes e pontos de vista das crianças devem ser considerados, uma vez que não existe uma verdade universal, mas diferentes pontos de vista, diferentes verdades.

O trabalho de tradução proposto por Santos (2002) parece-nos bastante consistente para que se efetive um não desperdício das experiências sociais. Seu objetivo é pensar numa construção de novas concepções de emancipação social de uma forma mais plural e "[...] criar justiça cognitiva a partir da imaginação epistemológica. 0 objectivo da tradução entre práticas e seus agentes é criar as condições para uma justiça social global a partir da imaginação democrática" (SANTOS, 2002, p. 274). O propósito mobilizador desta proposta é o de estabelecer uma emancipação social para os grupos cujas experiências são desperdiçadas e desconsideradas. O objetivo é denunciar esse desperdício, tirando da ausência o que está ausente, tornando visível o que estava invisibilizado.

Consideramos pertinente salientar que mudanças nas esferas sociais, políticas e econômicas também afetam a vidas das crianças. Quando falamos em produção de 
conhecimento sobre a infância, podemos afirmar que elas são invisibilizadas por concepções adultocêntricas. Trata-se de um olhar que compreende as crianças como incapazes, um "vir-a-ser". Esta produção de conhecimento está extremamente ligada ao lugar social que a criança vem ocupando historicamente na relação com o outro, em especial o outro adulto.

\section{A concepção moderna de infância: uma construção (em construção) social}

A concepção moderna de infância, tal qual conhecemos hoje, é uma construção histórica e social; portanto, não é uma categoria natural. A historiografia da infância procura compreender a inter-relação nas vertentes da história da família, da assistência e da educação, de forma a promover possibilidades de estudos em torno das condições de vida e da história social das crianças.

As contribuições do historiador Phillipe Ariès (1983), por exemplo, tiveram uma significativa repercussão nos espaços acadêmicos de educação e se transformou em fonte de inspiração para diversos trabalhos da área (PINTO, 1997). É inegável o mérito de suas obras, já que seus estudos abriram caminhos e possibilidades de diálogos sobre a infância, colocando em confronto posicionamentos epistemológicos sobre a construção da ideia moderna de infância.

A discussão a respeito de suas conclusões causou grande impacto; contudo, é necessário refletir sobre alguns aspectos da sua obra.

Seu estudo cronológico, a partir da Idade Média europeia, demonstrou que neste momento histórico não havia lugar para a infância: elas ficavam "misturadas" ao mundo dos adultos e nele submersas desde muito pequenas, mais especificamente até os sete anos de idade. A partir deste momento - compreendido como a idade da razão -, as crianças não precisariam mais de cuidados específicos das mães ou das amas, iniciando o processo de socialização no mundo adulto, participando de jogos e do trabalho.

A defesa de uma não existência do sentimento de infância na Idade Média, proposto pelo historiador, tem suscitado debates e distintos posicionamentos. Segundo 
Kuhlmann Jr. (2004), a entrada das crianças no mundo dos adultos aos sete anos não se dava de maneira imediata, mas por um processo de iniciação, ao longo do qual o aprendiz precisaria percorrer algumas etapas para adquirir diversos graus de autonomia, o que inspirou, inclusive, uma ideia de organização da educação escolar de acordo com as classes de idade (KUHLMAN JR., 2004).

Portanto, a não existência de um sentimento de infância não significa necessariamente que elas fossem negligenciadas ou desprezadas. Para Pinto (1997), o que acontecia, na verdade, era que, quando a criança demonstrava ser capaz de viver sem uma constante assistência da mãe ou da ama, teria adquirido um grau de discernimento sobre si e também sobre o mundo e, desta forma, se inseria de forma gradativa na vida dos adultos.

De acordo com Kuhlmann Jr., havia uma percepção da especificidade da infância na Idade Média, segundo a qual a criança “[...] era construída, em primeiro lugar pelo amor ou pela rejeição dos pais e aquele se manifesta no protagonismo da mãe durante o período da criação, acolhendo a criança, rejeitando-a, ou eventualmente, praticando o infanticídio" (Id., 2004, p. 17).

O uso dos conceitos sobre a infância em determinados tempos históricos revela também as formas como os adultos compreendem as crianças e suas concepções de infância. Estas interferem no comportamento das crianças, adolescentes e até dos adultos:

[...] modelando formas de ser e agir de acordo com as expectativas criadas nos discursos que passam a circular entre as pessoas, expectativas estas, que, por sua vez, correspondem aos interesses culturais, políticos e econômicos do contexto social mais amplo (JOBIM; SOUZA apud SOUSA; PEREIRA, 1998, p. 3).

As crianças estiveram - e estão - submetidas a uma invisibilidade social; mesmo hoje, suas especificidades não são consideradas, mas subjugadas e reprimidas pela racionalidade adulta. É necessário pensar que estas concepções se modificaram histórica e socialmente e necessitam ainda de mais avanços, para que a definição das crianças como cidadãs de direitos não permaneçam somente "no papel”. 
Com o lluminismo, por exemplo, inaugura-se, em certa medida uma preocupação com a criança. Contudo, tal preocupação não dizia respeito a suas peculiaridades; o interesse estava voltado ao pequeno adulto, ao homem de amanhã (SOUZA; PEREIRA, 1998). Neste momento histórico, a “[...] infância é compreendida como uma fase efêmera, passageira e transitória que precisa ser apressada. Crescer é tornar-se um ser de razão, e, esse amadurecimento, tal como faz frutas na estufa, precisa ser aligeirado" (NUNES; PEREIRA Apud SOUZA; PEREIRA, 1998, p. 5).

Com a ciência moderna, nasce um saber especializado, que também se estende às crianças e à infância, o qual tem como pressuposto a regulação e transformação do caos em ordem, com vistas à garantia de uma normalidade:

Como um desdobramento da máxima de que a ciência é o critério da verdade, ao especialista é conferida a autoridade da produção de "verdades" sobre a educação da criança na época moderna. Portanto, o psicólogo, o psicopedagogo, o fonoaudiólogo, o psicomotricista, o pediatra e até mesmo os profissionais da mídia assumem a função de caracterizar a criança e suas necessidades, definindo metas para sua educação e seu desenvolvimento (SOUZA; PEREIRA, 1998, p. 6).

Com a definição de padrões de normalidade e regulação, as crianças ficam à mercê de mais invisibilidades. Legitimados pela ciência moderna, os modelos de mensuração e classificação ditam as regras do comportamento infantil, do que é verdade e do que não é, do que é normal e do que é anormal. A Psicologia do Desenvolvimento incumbiu-se de "vigiar" o desenvolvimento humano, “[...] a partir de normas pré-concebidas de incentivo à maturação, selecionando e adaptando atividades "adequadas" para cada fase do desenvolvimento da criança" (SOUZA; PEREIRA, 1998, p. 6).

Para Souza (1996), a característica que marca as teorias do desenvolvimento do século XIX estabelece saberes que concebem conceitos universalizantes, que demarcam a natureza e o lugar social dos sujeitos de acordo com etapas e padrões normativos do desenvolvimento humano. O tempo cronológico e sua linearidade legitimam uma compreensão da infância como um estado transitório e inacabado.

Neste momento histórico, impõe-se a observação dos comportamentos exteriores à criança, considerando-os reveladores da sua identidade, por meio de movimentos, percepções e expressões - destaca-se a linguagem verbal - que constituem fatos 
psicológicos a serem observados. Medidas e classificações conferem um padrão de normalidade ao comportamento infantil, definindo o que cada criança consegue e deve fazer em determinada idade (FERREIRA, 2000). As crianças que não alcançassem o padrão de desenvolvimento encontravam-se fora da normalidade satisfatória. Portanto, o que se coloca é a racionalização da infância, legitimada pela ciência moderna.

A racionalização da infância continua a se legitimar nos tempos atuais. Por este motivo, Boaventura de Sousa Santos (2002) sugere a crítica ao paradigma da racionalidade. A ciência concebe a infância como um tempo de construção do indivíduo civilizado, de modo a conformar a infância civilizada de acordo com os padrões de normalidade.

\section{Infância, modernidade e globalização: as crianças como cidadãs de direitos}

As mudanças que se delineiam histórica e socialmente também influenciam diretamente a vida das crianças. O tempo aligeirado que normatiza a vida adulta, também o faz com a vida dos pequenos. A infância é por vezes compreendida como um tempo passageiro de preparação para a vida adulta e os saberes das crianças são desconsiderados, submetidos à ausência e à invisibilidade.

As crianças são sujeitos de direitos e merecem ser tratadas de forma respeitosa, participando efetivamente das questões que dizem respeito às suas vidas. Elas fazem parte deste mundo, e desejam tal participação. Suas múltiplas formas de se expressar, suas singularidades e jeitos de compreender a realidade podem contribuir para a forma como os adultos entendem e compreendem a sociedade. É necessário conceber que elas têm seus pontos de vista e seus saberes, colocá-los em confronto e diálogo com os pontos de vistas dos adultos de maneira horizontal e respeitosa se torna urgente.

Para Rizzini (2004), os efeitos gerados pela globalização são normativos em relação às crianças. Considerar suas perspectivas nos processos investigativos sobre o tema faz-se extremamente importante para que se formulem políticas e práticas concretas - que contribuam para o bem-estar das crianças. Estas políticas demonstram ser mais eficazes quando elas participam efetivamente dos debates que dizem respeito às 
suas próprias oportunidades. A globalização neoliberal impacta diretamente sobre a qualidade de vida de todos nós e, sobretudo, do grupo social da infância:

O impacto da globalização neoliberal na generalização de políticas globais que se centram na esfera económica e na promoção de apenas algumas franjas da população mundial, é um impacto determinante e também cerceador da qualidade de vida, principalmente dos grupos sociais mais excluídos, onde incluímos o grupo social da infância (TOMÁs; SOARES, 2004, p. 2).

No contexto de globalização neoliberal, as crianças são submetidas a exclusões, justificadas pelos indicadores de pobreza, marginalização e, também, à não participação das crianças em decisões. A situação da infância, como em outros grupos sociais, é afetada pelos efeitos dessa globalização, sofrendo situações de absurda barbárie, “[...] desde as meninas prostitutas na Tailândia, à proliferação da pornografia infantil na internet, à exploração de crianças de 5 anos presas ao teares na Índia" (TOMÁS; SOARES, 2004, p. 3).

Para refletir criticamente sobre estas situações, são pertinentes as contribuiçõos de Boaventura de Sousa Santos (1997, 1999, 2002, 2007), quando nos propõe as sociologias das ausências e das emergências. Com objetivo de trazer à tona as invisibilidades oriundas dos efeitos perversos do capitalismo e da globalização neoliberal, tem o intuito de colocar em cena as ausências, evitando o desperdício das muitas experiências sociais: neste caso, as experiências e saberes das crianças.

Pretendemos, a partir de suas contribuições (Id., 2007), propor aqui uma perspectiva que busca dar credibilidade aos diferentes saberes das crianças, colocando-os em diálogo com os dos adultos. Para tanto, é necessário sensibilizar nosso olhar mediante as múltiplas formas de as crianças se expressarem, considerando-as cidadãs de plenos direitos, principalmente com direito a voz:

E é justamente aqui que pensamos ser indispensável acrescentar a esta reflexão a ideia de considerar o grupo social da infância como um grupo com direitos específicos de participação, porque somente de tal forma conseguiremos centrar a reflexão sobre a exclusão social das crianças no seu grupo social e não indirectamente, através da análise das condições sociais que outros grupos em que ela está inserida (TOMÁS; SOARES, 2004, p. 4). 
Novas perspectivas de estudos e pesquisas que começaram a ganhar força no início do século XXI apresentam-se de extrema importância para colocar em evidência uma imagem da criança cidadã, com intuito de inseri-la no processo de cidadania, de modo a valorizar seus pontos de vistas e sua participação nos processos que dizem respeito a suas vidas.

Dentre as perspectivas que as defendem como sujeitos de direitos, podemos destacar a Sociologia da Infância. Esta é uma área que tem contribuído significativamente para reivindicar os direitos das crianças e questionar a posição de subalternidade que são submetidas mediante aos adultos (JAMES; PROUT, 1999; QVORTRUP, 1991; CORSARO, 1997; MAYALL, 2002; DEVINE 2002 apud TOMÁS; SOARES, 2004).

As contribuições da Sociologia da Infância apontam para uma nova concepção de criança e apresentam um novo campo de possibilidades. As crianças passam a ser compreendidas como atores sociais, com direito a voz e como produtoras de cultura e não apenas como submissas à geração adulta. Manuel Jacinto Sarmento (2002) colabora com este debate e ajuda-nos a pensar sobre as culturas infantis:

O imaginário infantil é inerente ao processo de formação e desenvolvimento da personalidade e racionalidade de cada criança concreta, mas isso acontece no contexto social e cultural que fornece as condições e as possibilidades desse processo. As condições sociais e culturais são heterogéneas, mas incidem perante uma condição infantil comum: a de uma geração desprovida de condições autónomas de sobrevivência e de crescimento e que está sob o controle da geração adulta. A condição comum da infância tem a sua dimensão simbólica nas culturas da infância (SARMENTO, 2002, p. 3).

O conceito culturas de infância vem se estabelecendo de forma contundente pela Sociologia da Infância como um elemento peculiar da categoria geracional. Entendemos por este conceito a real capacidade que as crianças possuem de construir modos de significação do mundo e de ação intencional, os quais são distintos dos modos de significação dos adultos (SARMENTO, 2002).

As crianças participam das realidades nas quais estão inseridas e as significam; devemos, portanto, considerar tal participação legitimando-as como cidadãs de direitos. Admitir que elas possam contribuir com seus pontos de vista consiste em reconhecer sua real capacidade. Escutar suas experiências, interpretando-as com a ajuda das próprias 
crianças deve ser entendido como possibilidade de ressignificar as hierarquias dos papéis sociais situados culturalmente (SOUZA; PEREIRA, 1998, p. 14).

É importante reafirmar, ainda, uma cidadania na infância, de modo a ponderar sobre a participação infantil como questão indispensável:

A ideia que defendemos é que a luta dos direitos das crianças tem que ser hoje também uma luta global, e que urge repensar as estratégias para proteger e promover os direitos das crianças, e que nessa luta e discussão as crianças sejam consideradas parceiras de pleno direito (TOMÁS; SOARES, 2004, p. 7).

Enfatizamos a urgência de se pensar em espaços e práticas sociais que garantam a participação das crianças. A ecologia de saberes se apresenta como uma possibilidade de refletir estas questões, e, assim, colocar em diálogo os diferentes pontos de vista, considerando os saberes dos pequenos legítimos, possíveis de serem considerados. É necessário, portanto, respeitar as crianças como verdadeiras participantes e merecedoras de seus direitos concretizados, como cidadãs ativas e potentes.

\section{Referências Bibliográficas}

ARIÈS, Philippe. História social da criança e da família. Guanabara, Rio de Janeiro, 1983.

FERREIRA, Maria Manuela. Salvar corpos, forjar a razão: contributo para uma análise crítica da criança e da infância como construção social em Portugal - 1880-1940. (Memórias da Educação-7). Instituto de Inovação Educacional, Lisboa, 2000. p.77-109.

KUHLMANN JR. Moysés e FERNANDES, Rogério. Sobre a história da infância. In: FARIA FILHO, Luciano Mendes (Org.). A infância e sua educação: materiais, práticas e representações. Belo Horizonte: Autêntica, 2004. p. 15-33.

RIZZINI, Irene. Infância e globalização: análise das transformações econômicas, políticas e sociais. In: Revista de Sociologia da Universidade de Lisboa, Problemas e Práticas, Portugal, v. 44, 2004. p. 11-26. 
PINTO, Manuel. A infância como construção social. In: PINTO, Manuel \& SARMENTO, Manuel Jacinto (Orgs.). As crianças: Contextos e Identidades. Portugal: Bezerra Editora, 1997.

SANTOS, Boaventura de Sousa. Pela mão de Alice. O social e o político na transição pósmoderna. São Paulo: Cortez, 1997.

. Porque é tão difícil construir uma teoria crítica? In: Revista Crítica de Ciências Sociais. Coimbra: Portugal, n.54, 1999. p. 197- 215.

- Para uma sociologia das ausências e uma sociologia das emergências. In: Revista Crítica de Ciências Sociais. Coimbra: Portugal, n.63, p. 237-280, 2002.

- Para além do Pensamento Abissal: Das linhas globais e uma ecologia de saberes. In: Revista Crítica de Ciências Sociais. Coimbra: Portugal, n. 78, p. 3-46, 2007.

SARMENTO, Manuel Jacinto. Imaginário e Culturas da Infância. Centro de Documentação e Informação sobre a Criança (CEDIC). Universidade do Minho: Instituto de Estudos da Criança, 2003.

; PINTO, Manuel. As crianças: Contextos e Identidades. Braga, Portugal; Centro

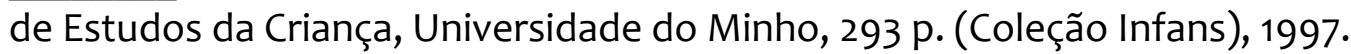

SOUZA, Solange Jobim. Ressignificando a psicologia do desenvolvimento: uma contribuição crítica à pesquisa da infância. In: KRAMER, Sônia e LEITE, Maria (Orgs.). Fios e desafios da pesquisa. São Paulo, Campinas: Papirus, 1996.

e PEREIRA, Rita Maria Ribes. Infância, conhecimento e contemporaneidade. In: KRAMER, Sonia e LEITE, Maria Isabel F. P. (Orgs.). Infância e produção cultural. Campinas, SP: Papirus, 1998.

TOMÁS, Catarina; SOARES, Natália. O cosmopolitismo infantil: uma causa (sociológica) justa. In: V Congresso Português de Sociologia - Sociedades contemporâneas:

reflexividade e acção. Cidade do Porto: Universidade do Minho, 2004. 
Recebido em: 17/03/2013 Aprovado em: 23/04/2013

Universidade do Estado de Santa Catarina - UDESC 